\title{
Influence of a history of smoking on short term (six month) clinical and angiographic outcome after successful coronary angioplasty
}

\author{
A G Violaris, A Thury, E Regar, R Melkert, P W Serruys
}

\begin{abstract}
Objectives-To assess the influence of smoking on restenosis after coronary angioplasty. Design and patients-The incidence of smoking on restenosis was investigated in 2948 patients. They were prospectively enrolled in four major restenosis trials in which quantitative angiography was used before and immediately after successful angioplasty and again at six months.

Results-Within the study population there were 530 current smokers, 1690 ex-smokers, and 728 non-smokers. Smokers were more likely to be men $(85.9 \%$ v 87.5\% v 65.3\%, current $v$ ex$v$ non-, $\mathrm{p}<0.001)$, to be younger $(54.0(9.0) v 57.0(9.1) v 59.9$ (9.4) years, $\mathrm{p}<0.001)$, to have peripheral vascular disease $(7.2 \%$ v $5.5 \%$ v $2.3 \%, \mathrm{p}<0.001)$, and have sustained a previous myocardial infarction $(42.9 \%$ v $43.9 \%$ v $37.9 \%, \mathrm{p}=0.022)$, but were less likely to be diabetic $(9.1 \% v 9.5 \% v 12.6 \%, \mathrm{p}=0.043)$ or hypertensive $(24.9 \% v 29.3 \% v 37.2, \mathrm{p}<0.001)$. There was no significant difference in the categorical restenosis rate $(>50 \%$ diameter stenosis) at six months $(35.28 \% v 35.33 \% v 37.09 \%$, current $v$ ex- $v$ non-), or the absolute loss $(0.29(0.54) v$ $0.33(0.52) v 0.35(0.55) \mathrm{mm}$, respectively; $\mathrm{p}=0.172)$.

Conclusions-Although smokers have a lower incidence of known predisposing risk factors for atherosclerosis, they require coronary intervention almost six years earlier than non-smokers and three years earlier than ex-smokers. Once they undergo successful coronary angioplasty, there appears to be no evidence that smoking influences their short term (six month) outcome, but because of the known long term effects of smoking, patients should still be encouraged to discontinue the habit.

(Heart 2000;84:299-306)
\end{abstract}

Keywords: coronary angioplasty; smoking; restenosis; quantitative angiography

Restenosis after successful coronary angioplasty remains a major limitation of the technique. ${ }^{12}$ Necropsy examination and recent intracoronary ultrasound studies suggest that it involves a combination of slow elastic recoil, vessel remodelling, thrombus incorporation, and late myointimal hyperplasia. ${ }^{2-4}$ Cigarette smoking can theoretically be involved in any of these mechanisms. Studies have shown that cigarette smoke can inhibit prostacyclin production by the vascular endothelial cells, ${ }^{5}$ impair endothelial function, ${ }^{6}$ activate platelets, ${ }^{7}$ and lower the baseline fibrinolytic activity in blood, ${ }^{8}$ thus enhancing platelet aggregation and thrombosis, ${ }^{69}$ all of which may be involved in the restenosis process. Cigarette smoke and its constituents can also cause acute coronary vasoconstriction, ${ }^{10}$ substantially altering local flow dynamics at the angioplasty site and causing increased platelet deposition and local thrombus formation, ${ }^{11}$ which further increases the possibilities of acute occlusion and long term restenosis. These theoretical considerations, and the large body of experimental and clinical evidence linking smoking habits with atherosclerosis, myocardial infarction, unstable angina, and sudden death, ${ }^{12}{ }^{13}$ have led to several studies on the role of smoking on restenosis after successful coronary angioplasty. ${ }^{14-19}$ The results have been conflicting, however, with two studies suggesting a positive relation $^{1415}$ and others suggesting no relation ${ }^{16-19}$ between the two.

Discrepancies between studies have arisen for various reasons. First, most have been retrospective analyses using small numbers of patients and thus subject to type B error. ${ }^{15}$ Second, they have almost invariably used visual assessment of the angiogram which has been shown to have wide interobserver and intraobserver variability. ${ }^{20}$ Third, the angiographic follow up rate has been generally poor and follow up has usually been performed for recurrence of symptoms, ${ }^{14} 16$ thus introducing an important selection bias.

We attempted to overcome these limitations by using a validated automated edge detection technique in a large series of patients undergoing successful balloon angioplasty and routine follow up angiographic assessment at a predetermined time interval. The aim of our study was to analyse the association between the information on smoking status available at the time of the procedure and the six month outcome.

\section{Methods}

PATIENTS

The study population comprised 2948 patients with significant primary stenoses in native coronary arteries who were prospectively enrolled into four major restenosis trials: CARPORT (coronary artery restenosis prevention on 
repeated thromboxane-antagonism study), PARK (post-angioplasty restenosis ketanserin trial), MERCATOR (multicentre European research trial with cilazapril after angioplasty to prevent transluminal coronary obstruction and restenosis), and MARCATOR (multicenter American research trial with cilazapril after angioplasty to prevent transluminal coronary obstruction and restenosis ). ${ }^{21-24}$ These showed that active treatment had no effect on restenosis or clinical outcome in the first six months after balloon angioplasty, so for the purposes of this study the data for the active and placebo groups were pooled. Patients were eligible for study entry if they were symptomatic or asymptomatic men, or women without child bearing potential, with stable or unstable angina pectoris, and proven angiographically significant narrowing in one or more major coronary arteries. Informed consent was obtained in all cases before the coronary angioplasty procedure. Patients with developing myocardial infarction and significant left main coronary artery disease were excluded from the study.

SMOKING HISTORY

A history of smoking was requested as part of the routine work up. Patients were asked if they had ever smoked and whether they were continuing to smoke, and their answers were recorded on the data sheet. Ex-smokers were defined as patients who had ever smoked regardless of the time when they stopped.

\section{ANGIOPLASTY PROCEDURE AND FOLLOW UP} ANGIOGRAPHY

Coronary angioplasty was performed with a steerable, moveable guide wire system by the femoral route. Standard balloon catheters were used. The choice of balloon type and brand, as well as inflation pressure and duration, were left to the discretion of the operator. Patients were followed up for six months, at which time a follow up study was performed. If symptoms recurred within six months, coronary angiography was carried out earlier. If no definite restenosis was present and the follow up time was below four months, the patient was asked to undergo further coronary arteriography at six months.

\section{Quantitative angiography}

Three coronary angiograms in all were obtained for each patient: before percutaneous transluminal coronary angioplasty (PTCA), after PTCA, and at angiographic follow up. The angiograms were recorded in such a manner that they were suitable for quantitative analysis by the computer assisted coronary angiography analysis system (CAAS) which has been described and validated earlier. ${ }^{25}$ To standardise the method of data acquisition and to ensure exact reproducibility of the angiographic studies, measures were taken as previously described and all angiograms were processed in a central angiographic core laboratory. ${ }^{21-24}$ Because the computer algorithm is unable to measure total occlusions, a value of $0 \mathrm{~mm}$ was substituted for the mini- mum lumen diameter and a value of $100 \%$ for the per cent diameter stenosis before PTCA. In these cases the post-angioplasty reference diameter was substituted for vessel size.

Angiographic definitions used

- Vessel size refers to the reference diameter of the relevant coronary segment and is represented by the interpolated reference diameter pre-PTCA.

- Minimum luminal diameter (MLD) is the point of maximum luminal narrowing in the analysed segment.

- Restenosis was assessed using both a categorical and a continuous approach. ${ }^{26}{ }^{27}$ For the categorical approach we used a cut off point of $>50 \%$ diameter stenosis at follow up. For the continuous approach we examined the absolute and relative loss, which may be a better reflection of the behaviour of the lesion during and after angioplasty, and therefore provide a better representation of the pathological process involved during follow up. ${ }^{26}$

- Acute gain and late loss represent the improvement in minimum luminal diameter achieved at intervention and the absolute change during follow up, respectively, measured in $\mathrm{mm}$ :

Acute gain $=$ MLD post-PTCA - MLD prePTCA

Absolute (or late) loss = MLD postPTCA - MLD at follow up

- Relative gain and relative loss depict the improvement in minimum luminal diameter achieved at intervention and the change during follow up respectively, normalised for vessel size:

Relative gain $=[$ MLD post-PTCA - MLD pre-PTCA $] /$ vessel size

Relative loss $=[$ MLD post-PTCA - MLD at follow up]/vessel size

- The absolute net gain is the MLD at follow up - MLD pre-PTCA.

- The net gain index is the net gain normalised for the vessel size:

Net gain index $=[M L D$ at follow up - MLD pre-PTCA]/vessel size

- The loss index is the late loss expressed as a fraction of the acute gain (loss/gain).

STATISTICAL ANALYSIS

Data were analysed using the SAS statistical software package. All values are expressed as mean (SD). Differences in categorical variables were assessed using the $\chi^{2}$ test. Analysis of variance was used to assess differences in continuous variables between the three groups. Whenever the difference between two of the three subgroups was tested, Bonferroni correction was applied. Comparisons of ranked variables (clinical end points) were tested using the Kruskal-Wallis test. The difference in eventfree survival time between the three groups was evaluated using the Kaplan-Meier method with the log rank and Wilcoxon tests. As multiple lesions within a given patient are not independent with respect to smoking, a patient based analysis was performed, using a single randomly selected lesion in patients with mul- 
tivessel angioplasty. To study the relation between a binary outcome variable (the occurrence of a clinical event) and multiple categorical and continuous determinants, multiple logistic regression analysis was used. To study the relation between continuous outcome variables and multiple categorical and continuous determinants, multiple linear regression analysis was used. Probability values of $p<0.05$ were considered significant.

\section{Results}

BASELINE PATIENT CLINICAL CHARACTERISTICS The study population comprised 2948 patients (3581 lesions, 1.22 lesions/patient) who successfully completed the study and had follow up quantitative angiography. The overall angiographic restudy rate was $86 \%$ of all patients undergoing successful PTCA. Within the study population there were 728 patients who had never smoked (889 lesions), 1690 patients who were ex-smokers (2057 lesions), and 530 patients who were still smoking (635 lesions) at the time of the index procedure.

The clinical and angiographic characteristics of the three groups are summarised in tables 1 and 2. There were notable differences in the baseline demographic characteristics of the three groups. There was a significantly higher proportion of men in the two smoking categories, and they were also younger. In addition they were more likely to have had a previous myocardial infarct and a history of peripheral vascular disease. Smokers were also less likely to be diabetic or to have a history of hypertension. There were pronounced differ- ences in anginal class, with smokers more likely to have angina in Canadian Cardiovascular Society (CCS) class IV and in drug treatment, with smokers and ex-smokers more likely to be taking calcium antagonists and aspirin. Haematologically, smokers were distinguished by having higher haemoglobin concentrations, packed cell volumes, and white cell counts.

CLINICAL FOLLOW UP

One hundred and eight $(20.3 \%)$ of the current smokers, $375(22.2 \%)$ of the previous smokers, and $185(25.4 \%)$ of the non-smokers had a clinical end point (redo PTCA, coronary artery bypass grafting (CABG), acute myocardial infarction, or death) during follow up $(p=0.085)$. When we compared the event-free survival using the log rank test the $p$ value was 0.088 , while the Wilcoxon test, which places more emphasis on early events, gave a comparable $\mathrm{p}$ value of 0.095 . The individual components for current, ex-, and non-smokers were: death, $0 \% \quad v \quad 0.12 \% \quad v \quad 0.55 \%$; myocardial infarction, $2.64 \%$ v $2.66 \%$ v $3.57 \%$; coronary artery bypass grafting, $1.89 \%$ v $2.66 \%$ v $2.75 \%$; and re-PTCA, $15.85 \%$ v $16.75 \% v$ $18.54 \%$, respectively $(p=0.057)$. The time course of clinical end points is summarised in fig 1 . The mean (SD) time to clinical follow up was similar in the three groups (current smokers 163 (44), ex-smokers 162 (44), nonsmokers 161 (45)).

To exclude the possibility that selection bias influenced our results we also examined the clinical end points in the $14 \%$ of the population in whom no quantitative angiographic meas-

Table 1 Baseline clinical characteristics of current smokers, ex-smokers, and non-smokers

\begin{tabular}{|c|c|c|c|c|}
\hline & Non-smokers & Ex-smokers & Current smokers & Significance level \\
\hline Number of patients & 728 & 1690 & 530 & \\
\hline Men & $65.3 \%$ & $87.5 \%$ * & $85.9 \%$ * & 0.000 \\
\hline Age (years) (mean (SD)) & $59.9(9.4)$ & $57.0(9.1)^{\star}$ & $54.0(9.0)$ & 0.000 \\
\hline Previous myocardial infarct & $37.9 \%$ & $43.9 \% \star$ & $42.9 \% \star$ & 0.022 \\
\hline Previous CABG & $3.6 \%$ & $4.6 \%$ & $4.0 \%$ & 0.470 \\
\hline Previous PTCA & $4.1 \%$ & $5.1 \%$ & $5.5 \%$ & 0.486 \\
\hline Diabetes mellitus & $12.6 \%$ & $9.5 \%{ }^{\star}$ & $9.1 \%$ * & 0.043 \\
\hline IDDM & $1.8 \%$ & $0.7 \%^{\star}$ & $0.4 \%$ * & 0.009 \\
\hline History of hypertension & $37.2 \%$ & $29.3 \%$ * & $24.9 \%{ }^{\star}$ & 0.000 \\
\hline History of hypercholesterolaemia & $32.0 \%$ & $31.5 \%$ & $31.9 \%$ & 0.965 \\
\hline History of PVD & $2.3 \%$ & $5.5 \%$ * & $7.2 \%$ * & 0.000 \\
\hline \multicolumn{5}{|l|}{ Anginal class } \\
\hline None & $6.3 \%$ & $5.8 \%$ & $4.3 \%$ & \\
\hline CCS class I & $9.8 \%$ & $11.7 \%$ & $11.3 \%$ & \\
\hline CCS class II & $34.6 \%$ & $32.6 \%$ & $29.4 \%$ & \\
\hline CCS class III & $31.5 \%$ & $29.9 \%$ & $29.1 \%$ & \\
\hline CCS class IV & $17.9 \%$ & $20.2 \%$ & $25.9 \%{ }^{\star}+$ & 0.032 \\
\hline Duration of angina (weeks) (mean (SD)) & $120(208)$ & $111(209)$ & $94(202)$ & 0.205 \\
\hline $\begin{array}{l}\text { Days since deterioration of angina (mean } \\
\text { (SD)) }\end{array}$ & $80(198)$ & $79(181)$ & $65(127)$ & 0.524 \\
\hline \multicolumn{5}{|l|}{ Drug treatment at screening } \\
\hline$\beta$ Blockers & $52.3 \%$ & $49.2 \%$ & $51.5 \%$ & 0.321 \\
\hline Calcium antagonists & $65.4 \%$ & $70.4 \%$ * & $72.3 \%$ * & 0.016 \\
\hline Nitrates & $62.1 \%$ & $66.7 \%$ & $66.2 \%$ & 0.659 \\
\hline Anticoagulants & $0.8 \%$ & $1.5 \%$ & $2.5 \%$ & 0.067 \\
\hline Platelet inhibitor & $64.3 \%$ & $63.5 \%$ & $67.7 \%$ & 0.203 \\
\hline Aspirin & $77.9 \%$ & $83.4 \% \star$ & $83.1 \%$ * & 0.032 \\
\hline Persantin & $10.6 \%$ & $11.6 \%$ & $15.2 \%$ & 0.121 \\
\hline \multicolumn{5}{|l|}{ Laboratory investigations (mean (SD)) } \\
\hline Haemoglobin $(\mathrm{g} / \mathrm{dl})$ & $8.72(0.86)$ & $8.89(0.80)$ & $8.99(0.86)^{\star}$ & 0.000 \\
\hline Packed cell volume (\%) & $41(4)$ & $42(4)$ & $43(4)^{\star}$ & 0.000 \\
\hline White cell count $(\mathrm{G} / \mathrm{l})$ & $7.05(2.94)$ & $7.34(2.09)$ & $8.26(2.24)^{\star} \dagger$ & 0.000 \\
\hline Platelet count $(\mathrm{G} / \mathrm{l})$ & $260(80)$ & $255(66)$ & $258(70)$ & 0.276 \\
\hline Total cholesterol (mmol/l) & $5.88(1.31)$ & $5.80(1.21)$ & $5.88(1.20)$ & 0.249 \\
\hline HDL cholesterol $(\mathrm{mmol} / \mathrm{l})$ & $1.20(0.34)$ & $1.13(0.56)$ & $1.11(0.69)$ & 0.477 \\
\hline LDL cholesterol (mmol/l) & $4.15(1.18)$ & $4.16(1.33)$ & $3.94(1.20)$ & 0.519 \\
\hline
\end{tabular}

${ }^{\star} \mathrm{p}<0.05 v$ non-smokers; $\mathrm{tp}<0.05 v$ ex-smokers.

CABG, coronary artery bypass graft; HDL, high density lipoprotein; IDDM, insulin dependent diabetes mellitus; LDL, low density lipoprotein; PTCA, percutaneous transluminal coronary angioplasty; PVD, peripheral vascular disease. 


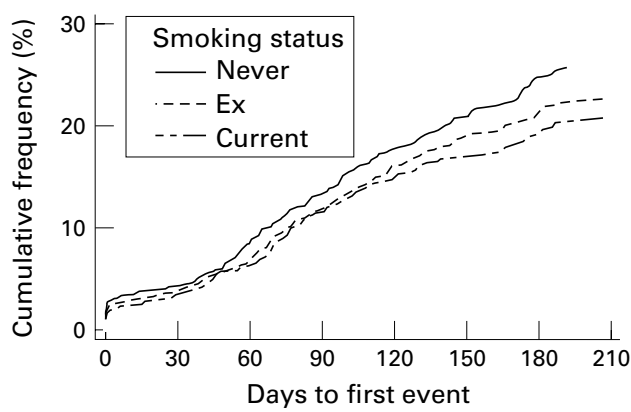

Figure 1 Cumulative distribution curve of clinical end points over time for current smokers, ex-smokers, and non-smokers.

urements were available, either before or after PTCA or at follow up, and who were therefore excluded from the study population. Of these patients $22.5 \%$ of the current smokers, $22.6 \%$ of the previous smokers, and $23.2 \%$ of the non-smokers had a clinical end point during follow up (redo PTCA, CABG, acute myocardial infarction, or death). The difference was not significant $(\mathrm{p}=0.99)$. The individual components of worse clinical end point such as death, myocardial infarction, coronary artery bypass grafting, and re-PTCA were $7.14 \%$, $2.04 \%, 6.12 \%$, and $7.14 \%$, respectively, for current smokers; $3.17 \%, 4.37 \%, 4.76 \%$, and $10.32 \%$ for ex-smokers; and $0.89 \%, 3.57 \%$, $7.14 \%$, and $11.61 \%$ for non-smokers. The differences in the individual clinical end points between the three groups were not significant $(\mathrm{p}=0.340)$.

QUANTITATIVE ANGIOGRAPHIC ANALYSIS AND CORONARY ANGIOPLASTY PROCEDURE A mean of 2.12 matched angiographic projections per lesion had satisfactory quantitative analysis performed at the central angiographic core laboratory before and after PTCA and at follow up. The distribution of lesions was significantly different in the three groups, with non-smokers having more lesions in the left anterior descending coronary artery and less in the right coronary artery than smokers and ex-smokers. Non-smokers were also more likely to have visible collaterals on baseline angiography (table 2).

There were no significant differences in the baseline quantitative angiographic measurements between the three groups apart from a slightly higher minimum lumen diameter before PTCA in current smokers (borderline significance, table 3). Smokers, however, required a longer duration of inflation (current) and inflation pressure (both current and ex-smokers) for a successful angioplasty procedure (table 2). After PTCA all quantitative angiographic measurements and derived variables were similar for the three groups (table 3, fig 2), again confirming the similarity in acute angiographic outcome.

At the six month angiographic follow up there was no significant difference in angio-

Table 2 Baseline angiographic and procedural data on current smokers, ex-smokers, and non-smokers

\begin{tabular}{|c|c|c|c|c|}
\hline & Non-smokers & Ex-smokers & Current smokers & Significance value \\
\hline Number of diseased vessels & & & & 0.347 \\
\hline $1-\mathrm{VD}$ & $65.0 \%$ & $62.9 \%$ & $66.0 \%$ & \\
\hline 2-VD & $26.4 \%$ & $29.5 \%$ & $25.7 \%$ & \\
\hline 3-VD & $7.8 \%$ & $7.2 \%$ & $7.6 \%$ & \\
\hline \multicolumn{5}{|l|}{ Lesion location } \\
\hline LAD & $50.6 \%{ }^{\star}+$ & $42.0 \%$ & $41.1 \%$ & 0.002 \\
\hline $\mathrm{LCx}$ & $22.8 \%$ & $24.7 \%$ & $23.8 \%$ & \\
\hline RCA & $26.5 \%{ }^{\star}+$ & $33.3 \%$ & $34.9 \%$ & 0.002 \\
\hline \multicolumn{5}{|l|}{ Lesion characteristics } \\
\hline Total occlusion pre-PTCA & $7.8 \%$ & $7.5 \%$ & $7.0^{\star}$ & 0.852 \\
\hline Concentric & $46.2 \%$ & $43.8 \%$ & $44.6 \%$ & 0.606 \\
\hline Tandem lesion & $3.8 \%$ & $4.2 \%$ & $3.9 \%$ & 0.871 \\
\hline Multiple irregularities & $8.3 \%$ & $7.5 \%$ & $8.4 \%$ & 0.742 \\
\hline Branch point in stenosis & $37.3 \%$ & $32.2 \%$ & $26.8 \%$ & 0.054 \\
\hline Branch point in dilatation site & $65.4 \%$ & $65.5 \%$ & $61.8 \%$ & 0.635 \\
\hline Coronary artery bend & $19.9 \%$ & $19.7 \%$ & $18.3 \%$ & 0.772 \\
\hline Calcified lesion & $12.5 \%$ & $12.8 \%$ & $10.2 \%$ & 0.275 \\
\hline Thrombus visible (pre-or post-PTCA) & $5.4 \%$ & $4.5 \%$ & $6.0 \%$ & 0.316 \\
\hline \multicolumn{5}{|l|}{ Degree of collateral supply } \\
\hline No collaterals & $78.5 \%{ }^{\star} \dagger$ & $85.1 \%$ & $87.7 \%$ & 0.005 \\
\hline Slight (minimal perfusion) & $5.9 \%{ }^{\star}+$ & $4.2 \%$ & $3.1 \%$ & 0.005 \\
\hline Medium (partial perfusion) & $6.8 \% \star+$ & $4.4 \%$ & $4.6 \%$ & 0.005 \\
\hline Major (complete perfusion) & $4.0 \% \dagger$ & $3.7 \%$ & $1.6 \%$ & 0.005 \\
\hline Not assessed & $4.8 \%{ }^{\star}+$ & $2.7 \%$ & $2.9 \%$ & 0.005 \\
\hline \multicolumn{5}{|l|}{ PTCA procedure data (mean $(S D))$} \\
\hline Nominal size of largest balloon (mm) & $2.87(0.42)$ & $2.89(0.43)$ & $2.87(0.42)$ & 0.342 \\
\hline Balloon to artery ratio & $1.13(0.18)$ & $1.12(0.18)$ & $1.12(0.19)$ & 0.402 \\
\hline Total number of inflations & $3.6(2.6)$ & $3.6(2.2)$ & $3.8(2.4)$ & 0.412 \\
\hline Total duration of inflation (s) & $301(267)$ & $323(264)$ & $344(288)^{\star}$ & 0.021 \\
\hline Maximum inflation pressure (atm) & $8.2(2.5)$ & $8.6(2.5)^{\star}$ & $8.7(2.5)^{\star}$ & 0.001 \\
\hline \multicolumn{5}{|l|}{ Post-PTCA result } \\
\hline Dissection at the dilated site & $37.5 \%$ & $34.2 \%$ & $31.3 \%$ & 0.069 \\
\hline Dissection type & & & & 0.255 \\
\hline Type A & $16.0 \%$ & $14.9 \%$ & $15.7 \%$ & \\
\hline Type B & $16.7 \%$ & $15.1 \%$ & $11.1 \%$ & \\
\hline Type C & $4.1 \%$ & $3.7 \%$ & $4.0 \%$ & \\
\hline Type D & $0.2 \%$ & $0.0 \%$ & $0.0 \%$ & \\
\hline Type E & $0.2 \%$ & $0.2 \%$ & $0.0 \%$ & \\
\hline Type F & $0.2 \%$ & $0.0 \%$ & $0.0 \%$ & \\
\hline Days to follow up (mean (SD)) & $161(45)$ & $162(44)$ & $163(44)$ & 0.553 \\
\hline
\end{tabular}

${ }^{\star} \mathrm{p}<0.05 v$ non-smokers; $\mathrm{tp}<0.05 v$ current smokers

$1,2,3-\mathrm{VD}$, one vessel, two vessel, three vessel disease; LAD, left anterior descending coronary artery; LCx, left circumflex coronary artery; PTCA, percutaneous transluminal coronary angioplasty; RCA, right coronary artery. 
Table 3 Quantitative angiographic analyses of current smokers, ex-smokers, and non-smokers

\begin{tabular}{|c|c|c|c|c|}
\hline & Non-smokers & Ex-smokers & Current smokers & Significance level \\
\hline \multicolumn{5}{|l|}{ Reference diameter (mm) } \\
\hline Before angioplasty & $2.60(0.54)$ & $2.65(0.53)$ & $2.64(0.54)$ & 0.116 \\
\hline After angioplasty & $2.65(0.52)$ & $2.69(0.50)$ & $2.67(0.51)$ & 0.129 \\
\hline At follow up & $2.67(0.56)$ & $2.71(0.56)$ & $2.71(0.54)$ & 0.200 \\
\hline \multicolumn{5}{|l|}{ Minimum lumen diameter (mm) } \\
\hline Before angioplasty & $0.96(0.40)$ & $1.00(0.40)$ & $1.02(0.38)^{\star}$ & 0.046 \\
\hline After angioplasty & $1.75(0.37)$ & $1.78(0.36)$ & $1.76(0.34)$ & 0.144 \\
\hline At follow up & $1.40(0.62)$ & $1.44(0.57)$ & $1.46(0.59)$ & 0.096 \\
\hline \multicolumn{5}{|l|}{ Differences in minimum lumen diameter } \\
\hline Absolute gain (mm) & $0.78(0.43)$ & $0.78(0.41)$ & $0.74(0.40)$ & 0.128 \\
\hline Relative gain & $0.31(0.16)$ & $0.30(0.16)$ & $0.29(0.15)$ & 0.074 \\
\hline Absolute loss (mm) & $0.35(0.55)$ & $0.33(0.52)$ & $0.29(0.54)$ & 0.172 \\
\hline Relative loss & $0.14(0.22)$ & $0.13(0.21)$ & $0.12(0.22)$ & 0.085 \\
\hline Absolute net gain & $0.43(0.61)$ & $0.45(0.56)$ & $0.45(0.61)$ & 0.870 \\
\hline Net gain index & $0.16(0.25)$ & $0.17(0.22)$ & $0.16(0.24)$ & 0.282 \\
\hline Loss index & $0.41(2.37)$ & $0.60(5.01)$ & $0.49(1.34)$ & 0.545 \\
\hline \multicolumn{5}{|l|}{ Percentage stenosis } \\
\hline Before angioplasty & $62.4 \quad(14.4)$ & $61.8(14.3)$ & $60.7(14.0)$ & 0.142 \\
\hline After angioplasty & $33.6(8.4)$ & $33.6(8.3)$ & $33.7(7.8)$ & 0.919 \\
\hline At follow up & $47.3 \quad(20.3)$ & $46.2 \quad(18.9)$ & $45.7 \quad(19.1)$ & 0.278 \\
\hline Diameter stenosis at follow up $>50 \%$ & $37.1 \%$ & $35.3 \%$ & $35.3 \%$ & 0.687 \\
\hline
\end{tabular}

Values are mean (SD) unless stated.

${ }^{\star} \mathrm{p}<0.05 v$ non-smokers.

graphic outcome between the three groups (table 3, fig 2). The overall restenosis rate for the study population was $35.8 \%$ using the categorical approach ( $>50 \%$ stenosis at follow up): current smokers $35.28 \%$, ex-smokers $35.33 \%$, non-smokers $37.09 \%(\mathrm{p}=0.687)$.

Additionally, the absolute and relative loss were also similar between current smokers, ex-smokers, and non-smokers: absolute loss, $0.29(0.54) v 0.33(0.52) v 0.35(0.55) \mathrm{mm}$ $(\mathrm{p}=0.172)$; relative loss, $0.12(0.22) \cup 0.13$ $(0.21) v 0.14(0.22)(\mathrm{p}=0.085)$ (table 3 , fig 3).
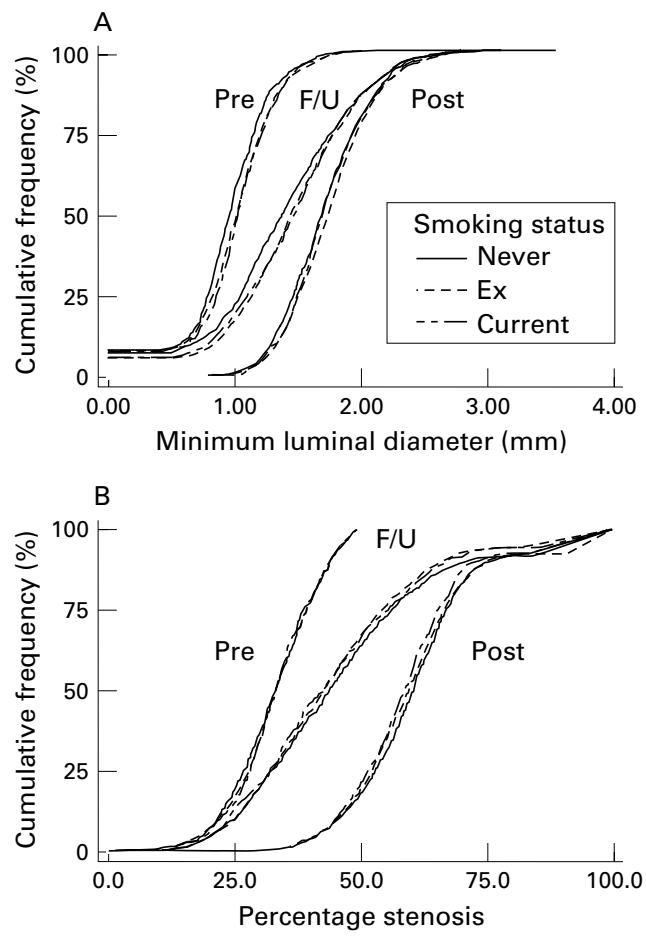

Figure 2 (A) Cumulative distribution curve of minimum lumen diameter before and after PTCA and at follow up, for current smokers, ex-smokers, and non-smokers. (B) Cumulative distribution curve of percentage stenosis before and after PTCA and at follow up for current smokers, ex-smokers, and non-smokers.
MULTIPLE LINEAR REGRESSION ANALYSIS

We have previously shown that vessel size, minimum lumen diameter before PTCA, absolute gain, and location of the left anterior descending coronary artery make a significant contribution to late angiographic outcome. ${ }^{28}$ Adding smoking to this model did not improve its predictive value. Least squares means for absolute loss were $0.348,0.311$, and 0.307 for non-smokers, ex-smokers, and current smokers, respectively. The $\mathrm{p}$ value of adding the variable "smoking" to the model was 0.15 , which is not significant.

To determine whether the tendency towards improved clinical outcome in patients who
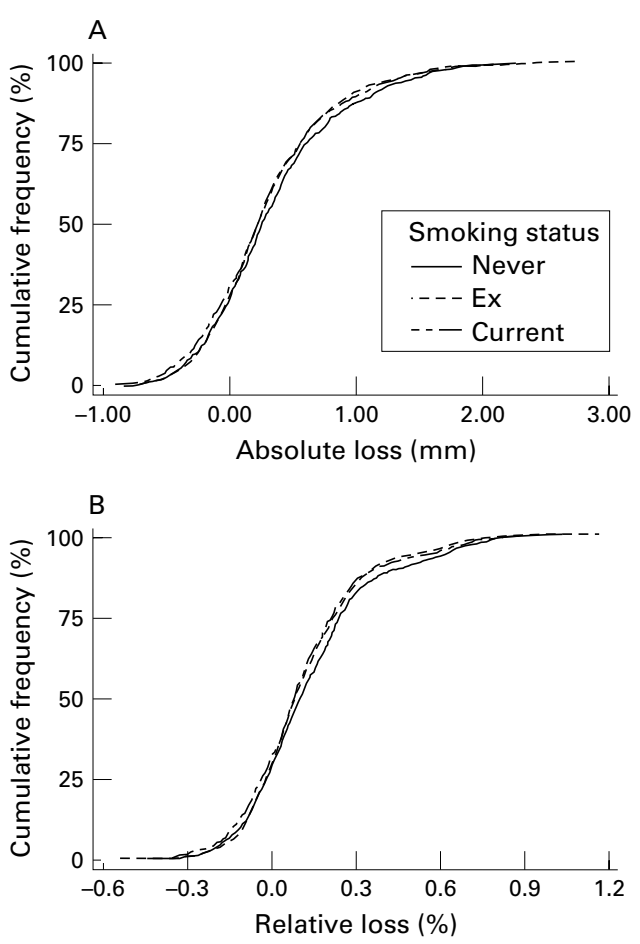

Figure 3 (A) Cumulative distribution curve of absolute loss for current smokers, ex-smokers, and non-smokers. (B) Cumulative distribution curve of relative loss for current smokers, ex-smokers, and non-smokers. 
smoke was related to differences in the underlying baseline characteristics, we corrected for these variables to see whether smoking had any significant independent predictive value. We performed logistic regression with the above mentioned baseline characteristics as covariates, resulting in a $p$ value for the variable smoking of 0.122 . This suggests that differences in clinical outcome were related to differences in baseline characteristics.

\section{Discussion}

Smoking is generally thought to have deleterious long term health effects, especially on the pulmonary and cardiovascular systems. However, the effect of smoking on the outcome of certain therapeutic procedures, such as coronary angioplasty, is poorly understood. The aim of our study was to analyse whether the smoking habit known at the time of the procedure affected the long term outcome.

Our results indicate that there are pronounced differences in baseline clinical, angiographic, and procedural characteristics between smokers and non-smokers undergoing coronary angioplasty. Smokers, despite having a lower incidence of known predisposing risk factors for atherosclerosis, require coronary intervention much earlier than non-smokers, but once they undergo successful coronary angioplasty their short term (six month) outcome is similar to non-smokers.

Two previous studies have suggested that smoking may be associated with an increased risk of restenosis. ${ }^{14}{ }^{15}$ Both studies, however, were in small patient populations, with a low angiographic follow up rate, performed for recurrence of symptoms, and without quantitative angiographic analysis. Using a large patient population with a high quantitative angiographic follow up rate at a predetermined six month time interval, our study has shown that smoking - a risk factor for atherosclerosis in general-is not a significant risk factor for restenosis.

There are several possible reasons for this. First, although cigarette smoking has been shown to be a risk factor for atherosclerosis, this is over the course of years, ${ }^{12}{ }^{13}$ whereas careful serial quantitative angiographic studies have shown that restenosis occurs in the first three to six months after intervention. ${ }^{1}$ Thus cigarette smoking may have little influence on the process over this short time frame. Second, the mechanisms of restenosis are still incompletely understood and are likely to involve differing contributions of slow elastic recoil, thrombus incorporation, vessel remodelling, and myointimal hyperplasia in each individual patient. $^{2-4}$ Cigarette smoking is unlikely to influence all of these mechanisms. Third, it is possible that the sudden withdrawal of cigarettes during and immediately after the procedure in the smokers may have had some favourable effect on vascular or haematological systems $^{29}$ which discouraged local platelet deposition, mural thrombus formation, and consequent restenosis. Fourth, there may be substantive differences in plaque characteristics between smokers and non-smokers, which could ameliorate any thrombogenicity associated with smoking. In support of this are the higher inflation pressures and duration of inflation required for successful dilatation of the atherosclerotic plaque in the smoking group, and also the published reports suggesting that lesions in smokers have a higher content of collagen ${ }^{30}$ and that the type of lesion that precipitates myocardial infarction in smokers is less severe and possibly generated by a different mechanism. ${ }^{29}{ }^{31}$

DIFFERENCES IN BASELINE CHARACTERISTICS There were significant differences in the baseline clinical, angiographic, and procedural characteristics between the smoking classes which could have been responsible for, or associated with, the outcome of the procedure. Smokers were younger, more likely to be male, to have peripheral vascular disease, and to have had a previous myocardial infarct. Conversely, they were less likely to have diabetes mellitus or a history of hypertension. These differences in baseline characteristics may be related to age. For example, as smokers tend to develop atherosclerosis at a younger age, they would be less likely to develop diseases of the older age group such as hypertension and diabetes. Many epidemiological studies have, however, also reported that smokers have significantly lower blood pressures than ex-smokers or non-smokers, ${ }^{32}$ but the mechanism for this negative relation is unknown. These differences in baseline clinical characteristics may have influenced clinical and angiographic outcome in various ways. For example, diabetic patients are more likely to have restenosis than non-diabetics, ${ }^{16} 33$ while dilatation of a vessel supplying previously infarcted territory is more likely to result in occlusion at the time of follow up angiography.

There were also significant differences in baseline haematological characteristics, with smokers having a higher haemoglobin, packed cell volume, and white cell count than non-smokers, and ex-smokers somewhere in between. There is evidence that smokers are also more likely to have a higher fibrinogen concentration and increased blood viscosity. ${ }^{34}$ What influence these variables may have on the clinical and angiographic outcome after intervention is unclear. Although increased fibrinogen concentrations have not been associated with a higher restenosis rate in a small series, ${ }^{35}$ raised white cell counts ${ }^{36}$ are known to be strong predictors of myocardial infarction ${ }^{37}$ and to be a marker of important cellular injury.

There were also differences in the distribution of lesions, with smokers having more lesions in the right coronary artery and fewer in the left anterior descending artery than nonsmokers, ex-smokers being somewhere in between. This is in keeping with other published reports suggesting a more proximal location of coronary lesions in hypercholesterolaemic non-smokers, and more distally situated lesions in normocholesterolaemic smokers. ${ }^{38}$ The lower incidence of left anterior descending coronary artery lesions, with their known higher incidence of restenosis, ${ }^{28}$ may be 
responsible for the trend towards less absolute and relative loss in smokers, with concordance from current smokers, through ex-smokers to non-smokers.

There were also significant differences in procedural characteristics, with lesions in smokers requiring a longer inflation time at a higher pressure. This suggests that there might be differences in plaque characteristics between the two groups, affecting clinical and angiographic outcome in both a positive and a negative way. This is supported by evidence suggesting that smokers have a significantly higher content of collagen in coronary endarterectomy specimens, ${ }^{30}$ while smoking has also been shown to increase arterial wall stiffness - a change that may be associated with reduction of medial porosity and reduced flow pulsatility.

\section{CLINICAL IMPLICATIONS}

In our study population, smokers - despite having a lower incidence of known predisposing risk factors for atherosclerosis, such as hypertension, diabetes, and hypercholesterolaemia-required coronary intervention almost six years earlier than non-smokers and three years earlier than ex-smokers. This was on a background of increased risk of previous myocardial infarction and peripheral vascular disease. According to our results, however, there appears to be no evidence that smoking at the time of the procedure affects the six month outcome. Therefore, smoking should not of its own be a contraindication for coronary angioplasty.

LIMITATIONS OF THE STUDY

Our study has several limitations. First, it was a retrospective analysis of prospectively gathered data and hence subject to the limitations inherent in any retrospective analysis. For example, it is possible that unknown variables not examined in our logistic regression model may account for the lack of a worse clinical and angiographic outcome in smokers. Second, our data only apply to successful angioplasty procedures and to a six month follow up period. Thus we do not know if smoking reduces the chances of acute success or increases the immediate acute complications of the procedure. Additionally, although restenosis is usually manifest in the first six months, we do not know whether a longer follow up period may in fact demonstrate progression of the angioplasty lesion in smokers. Third, we do not have objective verification of the patient's self reported smoking status as we did not specifically assess - for example, by periodic measurement of urinary products-whether supposed ex-smokers had truly stopped or whether they were continuing to smoke. This is especially pertinent as patients may give misleading answers in order to ensure the doctor's approval. It is also possible that, given the large effects of second hand smoke on arterial function, passive smoking could have affected the data in the ex-smokers and to a lesser extent the non-smokers, and thus led to an underestimate of the effects of smoking.
A further possibility is that our study may have been underpowered to detect a small enough difference between the groups. Given the number of patients and the restenosis rate (both categorical and continuous (absolute loss)) in the non-smoker group, our study has a power of $90 \%$ to detect a difference of $20 \%$ in the smoking group for the categorical restenosis rate, and $0.10 \mathrm{~mm}$ for the absolute loss. We would consider both of these to be clinically significant, but the fact remains that if the effect of smoking were below these levels we would have been unable to detect it.

We also do not have information on changes in smoking habits during the follow up period and their possible effect on outcome. However, subanalysis of the 1048 patients (taking part in the CARPORT and PARK studies), whose smoking status was ascertained at the one and six month follow up visit, revealed that 64 of the 166 current smokers (38.55\%) stopped smoking by the time of the six month follow up visit. Of these, 18 had a clinical end point compared with 25 who continued to smoke. However, the numbers in this subanalysis are too small to allow a meaningful comparison.

Ideally, future studies should include observation of the changes in smoking habits over time as well as intravascular ultrasound assessment of the acute results of intervention and the mechanism of subsequent restenosis; by differentiating between slow recoil, thrombus formation/incorporation, and intimal hyperplasia this would make it easier to show benefit from cessation of smoking.

\section{CONCLUSIONS}

Our results indicate that smokers, despite having a lower incidence of known predisposing risk factors for atherosclerosis, require coronary intervention almost six years earlier than non-smokers and three years earlier than ex-smokers. This is on a background of increased risk from previous myocardial infarction and peripheral vascular disease. Once they undergo successful coronary angioplasty there appears to be no evidence that smoking influences short term (six month) outcome. However, because of the known long term effects of smoking, patients should still be encouraged to discontinue the habit.

We gratefully acknowledge the continually high quality quantitative angiographic analysis from the staff of the angiographic tative core laboratory at Cardialysis, Rotterdam, and the sponsorship of Glaxo Group Research Ltd, Middlesex, UK, F Hoffman-La Roche Ltd, Basel, Switzerland, and Janssen Research Foundation, Beerse, Belgium. We would also like to acknowledge the work of the 31 European, 40 American, and seven Canadian centres which participated in the CARPORT, MERCATOR, MARCATOR, and PARK studies and without whose assistance this study would not have been possible. A full list of all participating centres can be found in references 21-24.

AGV was the recipient of a Wellcome Trust International Research fellowship, 1992-1995.

1 Serruys PW, Luijten HE, Beatt KJ, et al. Incidence of restenosis after successful coronary angioplasty: a timerelated phenomenon. A quantitative angiographic study in 342 consecutive patients at $1,2,3$, and 4 months. Circulation $1988 ; 77: 361-71$

2 Hong MK, Mehran R, Mintz GS, et al. Restenosis after coronary angioplasty. Curr Probl Cardiol 1997;22:1-36.

3 Waller BF, Pinkerton CA, Orr CM, et al. Restenosis 1 to 24 Waller BF, Pinkerton CA, Orr CM, et al. Restenosis 1 to 24
months after clinically successful coronary balloon months after clinically successful coronary balloon diol 1991;1 17:58-70B. 
4 Mintz GS, Kent KM, Pichard AD, et al. Intravascular ultrasound insights into mechanisms of stenosis formation and sound insights into mechanisms of ste

5 Nadler JL, Brinkman HJ, van Mourik JA, et al. Cigarette smoking inhibits prostacyclin formation. Lancet 1983; 1248-50

6 Benowitz NL. Pharmacologic aspects of cigarette smoking and nicotine addiction. $N$ Engl f Med 1988;319:1318-30.

7 Davis JW, Hartman CR, Lewis HD. Cigarette smoking induced enhancement of platelet function: lack of prevention by aspirin in men with coronary artery disease. $\mathcal{f} \mathrm{Lab}$ Clin Med 1985;105:479-83.

8 Allen RA, Kluft C, Brommer JP. Effect of chronic smoking on fibrinolysis. Atherosclerosis 1985;5:443-50.

9 Galea G, Davidson RJL. Haematological and haemorheological changes associated with cigarette smoking. $\mathcal{F}$ Clin Pathol 1985;38:978-85.

10 Quillen JE, Rossen JD, Oskarsson HJ, et al. Acute effect of cigarette smoking on the coronary circulation: constriction of epicardial and resistance vessels. $\mathcal{F}$ Am Coll Cardiol 1993; 22:642-7.

11 Badimon L, Badimon JJ. Mechanisms of arterial thrombosis in non parallel streamlines: platelet thrombi grow on the apex of stenotic severely injured vessel wall. Experiment study in a pig model. F Clin Invest 1989;84:1134-44.

12 Doll R, Peto R. Mortality in relation to smoking: twenty years' observations of male British doctors. BMF 1976;ii: 1525-36.

13 Hallstrom AP, Cobb LA, Ray R. Smoking as a risk factor for recurrence of sudden death. $N$ Engl 7 Med 1986;314:2715.

14 Myler RK, Topol EJ, Shaw RE, et al. Multiple vessel coronary angioplasty: classification, results, and patterns of restenosis in 494 consecutive patients. Cathet Cardiovasc Diagn 1987;13:1-15.

15 Galan KM, Deligonul U, Kern MJ, et al. Increased frequency of restenosis in patients continuing to smoke cigarettes after percutaneous translurninal coronary angiocigarettes after percutaneous translurnir
plasty. Am 7 Cardiol 1988;61:260-3.

16 Holmes DR, Vlietstra RE, Smith HC, et al. Restenosis after percutaneous transluminal coronary angioplasty (PTCA): a report from the PTCA registry of the National Heart, Lung, and Blood Institute. Am f Cardiol 1984;53:77-81C.

17 Vandormael MG, Deligonul U, Kern MJ, et al. Multilesion coronary angioplasty: clinical and angiographic follow-up. $\exists$ Am Coll Cardiol 1987;10:246-52.

18 Macdonald RG, Henderson MA, Hirshfeld JW, et al. Patient-related variables and restenosis after percutaneous transluminal coronary angioplasty - a report from the MHEART Group. Am f Cardiol 1990;66:926-31.

19 Kotamaki M, Laustiola K, Syvanne M, et al. Influence of continued smoking and some biological risk factors on restenosis after percutaneous transluminal coronary angioplasty. F Intern Med 1996;240:293-301.

20 Haase J, Keane D, di Mario C, et al. How reliable are geometric coronary measurements? In vitro and in vivo validation of digital and cinefilm based quantitative coronary analysis systems. In: Serruys PW, Foley DP, de Feyter PJ, eds. Quantitative coronary angiography in clinical practice. PJ, eds. Quantitative coronary angiography in clinical practice

21 Serruys PW, Rutsch W, Heyndrickx GR, et al. Prevention of restenosis after percutaneous transluminal coronary angioomized, double-blind, placebo-controlled trial. Coronary artery restenosis prevention on repeated thromboxaneantagonism study (CARPORT). Circulation 1991;84 1568-80.

22 MERCATOR study group. Does the new angiotensin converting enzyme inhibitor cilazapril prevent restenosis after percutaneous transluminal coronary angioplasty? Results of the MERCATOR study: a multicenter, randomized, double-blind, placebo-controlled trial. Circulation 1992;86: $100-10$

23 Serruys PW, Klein W, Tijssen JGP, et al. Evaluation of ketanserin in the prevention of restenosis after percutaneous transluminal coronary angioplasty: a multicentre randomized double blind placebo controlled trial. The postangioplasty restenosis ketanserin (PARK) trial. Circulation 1993;88:1588-601.

24 Faxon DP, on behalf of the MARCATOR study group. Effect of high dose angiotensin converting enzyme nhibition on restenosis. final results of the MARCA study, a multicenter, double-blind, placebo-controlled trial of cilazapril. I Am Coll Cardiol 1995;25:362-9.

25 Serruys PW, Foley DP, de Feyter PJ, eds. Quantitative coronary angiography in clinical practice. Dordrecht: Kluwer Academic Press, 1994.

26 Serruys PW, Foley DP, de Feyter PJ. Restenosis after coronary angioplasty: a proposal of new comparative approaches based on quantitative angiography. Br Heart 7 1992;68: $417-24$

27 Kuntz RE, Baim DS. Defining coronary restenosis. Newer clinical and angiographic paradigms. Circulation 1993;88: $1310-23$

28 Foley DP, Melkert R, Serruys PW, on behalf of the CARPORT MERCATOR, MARCATOR, and PARK investigators. Influence of coronary vessel size on renarrowing process and late angiographic outcome after successful balloon angioplasty. Circulation 1994;90:1239-51.

29 Barbash Gl, White HD, Modan M, et al. Significance of smoking in patients receiving thrombolytic therapy for acute myocardial infarction. Experience gleaned from the international tissue plasminogen activator/streptokinase mortality trial. Circulation 1993;87:53-8.

30 Ribeiro P, Jadhav AV, Walesby R, et al. Collagen content of atherosclerotic arteries is higher in smokers than in non-smokers. Lancet 1983; i: 1070-2.

31 de Chillou C, Riff P, Sadoul N, et al. Influence of cigarette smoking on rate of reopening of the infarct-related coronary artery after mvocardial infarction: a multivariate analysis. $\mathcal{F}$ Am Coll Cardiol 1996;27:1662-8.

32 Green MS, Jucha E, Luz Y. Blood pressure in smokers and nonsmokers: epidemiological findings. Am Heart $\mathcal{F}$ 1986; 111:939-40.

33 Asakura Y, Suzuki M, Nonogi H, et al. Restenosis after percutancous transluminal coronary angioplasty in patients with non-insulin-dependent diabetes mellitus (NIDDM). $\mathcal{F}$ Cardiovasc Risk 1998;5:331-4.

34 Emst E, Koenig W, Matrai A, et al. Blood rheology in healthy cigarette smokers. Arteriosclerosis 1988;8:385.

35 Schurnacher M, Eber B, Tiran A, et al. Fibrinogen values in patients with and without restenosis following percutaneous transluminal coronary angioplasty. Cardiology 1992;80: $345-8$.

36 Friedrnan GD, Siegelaub AB, Seltzer CC, et al. Smoking habits and the leucocyte count. Arch Environ Health 1973; 26:137-43.

37 Knoke JD, Hunninghake DB, Heiss G. Physiological markers of smoking and their relation to coronary heart disease. The lipid research clinics coronary primary prevention trial. Arteriosclerosis 1987;7:477-82.

38 Sugrue D, Thompson GR, Oakley CM, et al. Contrasting patterns of coronary atherosclerosis in normocholesteroaemic smokers and patients with hypercholesterolaemia. BMF 1981;283:1358-60. 